\title{
Clinical and chest CT presentations from 27 patients with COVID-19 pneumonia in Mogadishu, Somalia: a descriptive study
}

Yahye Garad Mohamed ${ }^{1}$, Mohamed Farah Yusuf Mohamud ${ }^{1 *}$ D, M. Sabri Medişoğlu², Ihsan Yavuz Atamaca ${ }^{2}$ and Ibrahim Hussein $\mathrm{Ali}^{2}$

\begin{abstract}
Background: Coronavirus disease 2019 (COVID-19) is an acute viral pneumonia that had recently been found in humans. The first case was discovered in Wuhan, Hubei province, China, in December 2019. In this article, we aimed to demonstrate the clinical and radiological characteristics of COVID-19 patients in Somalia from 20 March 2020 to 20 April 2020.

Results: Twenty-seven patients that had a positive RT-PCR test between 20 March 2020 and 20 April 2020 were retrospectively observed. This study included 19 (70.4\%) males and 8 (29.6\%) females, and the mean age and range were 43 years (SD \pm 14.0 ) and 27-70 years, respectively. The majority (59.3\%) of COVID-19-infected patients had no obvious history of exposure to infected patients. The participants of our study mostly presented with dry cough 24 (88.9\%) patients, fever 19 (70.4\%), myalgia 18 (66.6\%), and sore throat 16 (59.3\%). Twenty-five of 27 patients had abnormal chest $C$, while 2 (7.4\%) patients had normal chest $C$. The most common patterns of abnormality seen on chest $C T$ in patients with COVID-19 were ground-glass opacity (GGO) 74.1\%, crazy paving pattern 18.5\%, consolidation 14.8\%, and mixed GCO 11.1\%. Also, the most common predominant lesion distributions were bilateral lung involvement (88.9\%), peripheral distribution (77.8\%), and lower lung predominance (63\%). Particularly, lung cavitation, discrete pulmonary nodules, pleural effusion, and underlying pulmonary fibrosis or emphysema had not been observed.

Conclusion: Dry cough, fever, myalgia, and sore throat were the most clinical presentations. GGO, crazy paving pattern, patchy consolidation, and mixed GCO were the typical chest $C T$ manifestations.
\end{abstract}

Keywords: Coronavirus disease 2019, Chest CT, Pneumonia, RT-PCR

\section{Background}

Coronavirus disease 2019 (COVID-19) is an acute viral pneumonia that was recently found in humans. The first case was discovered in Wuhan, Hubei province, China, in December 2019. COVID-19 is described by the World Health Organization (WHO) as an international public health emergency of public concern and also declared COVID-19 as a pandemic [1-3].

\footnotetext{
* Correspondence: m.qadar59@gmail.com

${ }^{1}$ Mogadishu Somali Turkish Training and Research Hospital, Mogadishu, Somalia

Full list of author information is available at the end of the article
}

Chen et al. demonstrated that history of exposure, clinical features, results of lab tests, and chest computed tomography $(\mathrm{CT})$ findings were the basic diagnostic parameters of COVID-19 [4]. Fever, cough, shortness of breath (SOB), fatigue, and myalgia were the common clinical manifestations of COVID-19 patients [5]. As recently reported, chest $\mathrm{CT}$ indicates typical radiographic features in almost all COVID-19 patients, consisting of ground-glass opacities (GGOs), bilateral pulmonary consolidations, and/or interstitial changes with a peripheral distribution [6]. In this article, we report the clinical and radiological findings of twenty-seven patients with confirmed COVID-19 pneumonia in Somalia.

\section{Springer Open}

(c) The Author(s). 2020 Open Access This article is licensed under a Creative Commons Attribution 4.0 International License, which permits use, sharing, adaptation, distribution and reproduction in any medium or format, as long as you give appropriate credit to the original author(s) and the source, provide a link to the Creative Commons licence, and indicate if changes were made. The images or other third party material in this article are included in the article's Creative Commons licence, unless indicated otherwise in a credit line to the material. If material is not included in the article's Creative Commons licence and your intended use is not permitted by statutory regulation or exceeds the permitted use, you will need to obtain permission directly from the copyright holder. To view a copy of this licence, visit http://creativecommons.org/licenses/by/4.0/. 


\section{Methods}

The medical ethics committee approval letter of this retrospective study was received from the institutional review board of the hospital, and written patient informed consent was waived.

\section{Patients}

From March 20 to April 20, 2020, a clinical and chest CT imaging data of 27 patients (mean age, $43 \pm 14$ years; $70.4 \%$ male and $29.6 \%$ female) with laboratoryconfirmed reverse transcriptase polymerase chain reaction (RT-PCR) assay with throat swab samples diagnosed as SARS-CoV-2 pneumonia were included in this study.

The throat swab samples were collected for RT-PCR in accordance with the WHO guidelines [7]. The diagnosis of COVID-19 was confirmed when RT-PCR test results were positive. We excluded all the patients with negative severe acute respiratory syndrome coronavirus 2 (SARS-CoV-2) test results, pregnant women, and children ( $<18$ years) from this study.

All demographic characteristics, clinical signs and symptoms, laboratory results, and chest CT imaging data were retrospectively reviewed from the patient's electronic medical records in Mogadishu Somalia Turkey Training and Research Hospital and De Martino Hospital information system (HIS).

The clinical data analyzed were as follows: age, sex, comorbid conditions, exposure history, signs and symptoms (fever, dry cough, SOB, myalgia, sore throat, headache, diarrhea, vomit, and nausea), and laboratory results (C-reactive protein, leukocytes, lymphocytes, and neutrophils).

\section{Imaging technique and interpretation}

All the patients in this study underwent non-enhanced chest CT examinations for detecting SARS-CoV-2 pneumonia in the supine position during end-inspiration.

CT data was obtained using a 16-slice configuration CT scanner (SOMATOM Emotion Siemens Healthineers Germany). The protocols were as follows: tube voltage, $120 \mathrm{kVp}$; automatic tube current modulation, 30-70 mA; and rotation time, $0.75 \mathrm{~s}$. All images were then reconstructed with a slide thickness of $0.75-1.50 \mathrm{~mm}$

Two radiologists (with 12 and 10 years of experience in thoracic CT) evaluated all imaging features blindly and independently in consensus.

The epidemiological history, clinical signs and symptoms (fever, dry cough, shortness of breath, and myalgia or fatigue), and laboratory tests were available for both radiologists.

We described three distributions: lung region, craniocaudal, and transverse. The main CT features included ground-glass opacities (GGO), mixed GGO, consolidation, crazy paving, air bronchogram, reticular pattern, subpleural linear opacity, bronchial dilatation, cavitation, intrathoracic lymph node enlargement, and pleural effusions. All terms were defined in accordance with the Fleischer Society guidelines [8].

\section{Statistical analysis}

Statistical software SPSS (version 23.0, IBM) was used for all statistical analyses. Categorical variables were displayed as counts and percentages, and continuous variables were reported as mean \pm standard deviation and range.

\section{Results}

Clinical, laboratory, and radiological data of 27 patients performed oropharyngeal swab tests and confirmed as 2019-nCoV were included in this study. Epidemiologically, there were two main groups of patients: 11 (40.7\%) were healthcare workers who had close contact with patients at the hospital who had confirmed COVID-19 pneumonia and the remaining 16 (59.3\%) did not have any obvious history of exposure.

There were $19(70.4 \%)$ males and 8 (29.6\%) females studied; the mean age of patients was $43 \pm 14.0$ ranging from 27 to 70 years (Table 1). Comorbidities were present in $6(22.2 \%)$ patients, with diabetes being the most common comorbidity, followed by hypertension and renal failure. Only one chronic obstructive pulmonary disease (COPD) patient was identified (Table 1).

The clinical features and laboratory findings of our patients are summarized in Table 1 . The most common symptoms at onset were dry cough 24 (88.9\%) patients, fever 19 (70.4\%), myalgia 18 (66.6\%), and sore throat 16 (59.3\%). Other non-specific symptoms included headache $5(18.5 \%)$ patients, diarrhea 4 (14.8\%), vomiting 4 (14.8\%), and nausea $2(7.4 \%)$, whereas $4(14.8 \%)$ patients had no obvious symptoms.

In the laboratory results, leukocytes of 21 (77.8\%) patients were in the normal range, while in $4(14.8 \%)$ patients below the normal range and in $2(7.4 \%)$ patients above the normal range. Lymphocytes were below the normal range in most of the patients 21 (77.8\%), while $19(70.4 \%)$ patients had neutrophils above the normal range. Patients with increased CRP were more than those within the normal range (Table 1 ).

As shown in Table 2, 25 (92.6\%) of 27patients had abnormal chest CT, while $2(7.4 \%)$ patients had normal chest CT. The most common patterns seen on chest CT in patients with COVID-19 were GGO 20 (74.1\%) patients (Fig. 1), crazy paving pattern 5 (18.5\%) patients (Fig. 2), patchy consolidation 4 (14.8\%) patients, and mixed GCO 3 (11.1\%) patients (Fig. 3). The most common predominant lesion distributions were bilateral lung involvement (88.9\%), peripheral distribution (77.8\%), and lower lung predominance (63\%) (Fig. 4a, b). 
Table 1 Clinical characteristics and laboratory results patients with SARS-CoV-2 pneumonia

\begin{tabular}{|c|c|}
\hline Patient characteristics & Patients $(n=27)$ \\
\hline \multicolumn{2}{|l|}{ Patient demographics } \\
\hline Male & $19(70.4 \%)$ \\
\hline Female & $8(29.6 \%)$ \\
\hline Age (years), mean \pm SD (range) & $43 \pm 14.0(27-70)$ \\
\hline \multicolumn{2}{|l|}{ Exposure history } \\
\hline Exposure to positive patients & $11(40.7 \%)$ \\
\hline Unknown exposure & $16(59.3 \%)$ \\
\hline \multicolumn{2}{|l|}{ Comorbid conditions } \\
\hline Diabetes & $6(22.2 \%)$ \\
\hline Hypertension & $3(11.1 \%)$ \\
\hline Renal failure & $3(11.1 \%)$ \\
\hline COPD & $1(3.7 \%)$ \\
\hline Liver disease & $1(3.7 \%)$ \\
\hline \multicolumn{2}{|l|}{ Signs and symptoms } \\
\hline No obvious symptoms & $4(14.8 \%)$ \\
\hline Fever & $19(70.4 \%)$ \\
\hline Dry cough & $24(88.9 \%)$ \\
\hline $\mathrm{SOB}$ & $6(22.2 \%)$ \\
\hline Myalgia & $18(66.6 \%)$ \\
\hline Sore throat & $16(59.3 \%)$ \\
\hline Headache & $5(18.5 \%)$ \\
\hline Diarrhea & $4(14.8 \%)$ \\
\hline Vomit & $4(14.8 \%)$ \\
\hline Nausea & $2(7.4 \%)$ \\
\hline \multicolumn{2}{|l|}{ Laboratory test } \\
\hline \multicolumn{2}{|c|}{ C-reactive protein (mg/L; normal range $0-10$ ) } \\
\hline Increased & $21(77.8 \%)$ \\
\hline Decreased & $0(0 \%)$ \\
\hline Normal & $4(14.8 \%)$ \\
\hline \multicolumn{2}{|c|}{ Leukocytes (normal range 4-10 × 109/L) } \\
\hline Increased & $2(7.4 \%)$ \\
\hline Decreased & $4(14.8 \%)$ \\
\hline Normal & $21(77.8 \%)$ \\
\hline \multicolumn{2}{|c|}{ Lymphocytes (normal range 20-40\%) } \\
\hline Increased & $0(0 \%)$ \\
\hline Decreased & $21(77.8 \%)$ \\
\hline Normal & $6(22.2 \%)$ \\
\hline \multicolumn{2}{|l|}{ Neutrophils (normal range 50-70\%) } \\
\hline Increased & $19(70.4 \%)$ \\
\hline Decreased & $0(0 \%)$ \\
\hline Normal & 8 (29.6\%) \\
\hline
\end{tabular}

Table 2 Imaging findings of patients with SARS-CoV-2 at presentation

\begin{tabular}{ll}
\hline Chest CT finding & Patients $(n=27)$ \\
\hline Patterns of the lesion & \\
Ground-glass opacification & $20(74.1 \%)$ \\
Mixed ground-glass opacities and consolidation & $3(11.1 \%)$ \\
Consolidation & $4(14.8 \%)$ \\
Crazy paving pattern & $5(18.5 \%)$ \\
Air bronchogram sign & $2(7.4 \%)$ \\
Reticular pattern & $1(3.7 \%)$ \\
Subpleural linear opacity & $2(7.4 \%)$ \\
Bronchial dilatation & $2(7.4 \%)$ \\
Lymphadenopathy & $1(3.7 \%)$ \\
Cavitation & $0(0 \%)$ \\
Pleural effusion & $0(0 \%)$ \\
Distribution & \\
Craniocaudal distribution & \\
Upper lung predominance & \\
Lower lung predominance & $1(3.7 \%)$ \\
No craniocaudal distribution & $17(63 \%)$ \\
Transverse distribution & $9(33.3 \%)$ \\
Central & \\
Peripheral & $2(7.4 \%)$ \\
No transverse distribution & $1(3.7 \%)$ \\
Lung region distribution & $21(77.8 \%)$ \\
Unilateral & $6(22.2 \%)$ \\
No lung region distribution & \\
\hline
\end{tabular}

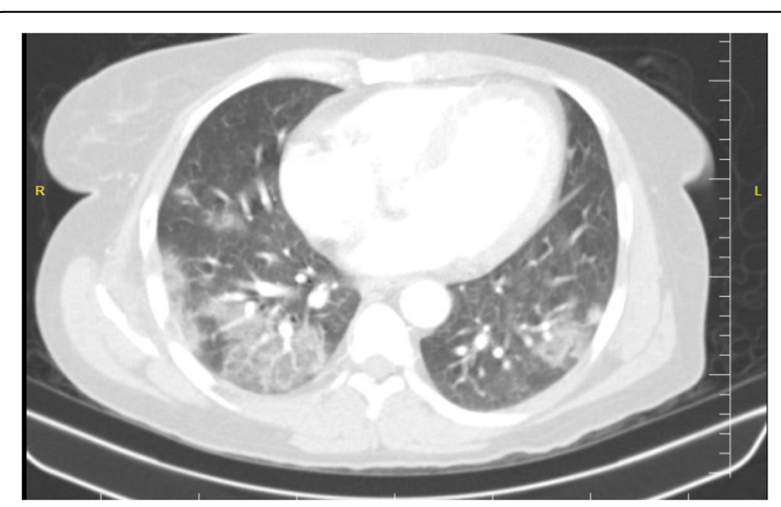

Fig. 1 An axial chest CT from a 47-year-old woman with COVID-19 pneumonia. Non-contrast-enhanced chest CT image showing multiple peripheral ground-glass opacities distributed in the bilateral multiple lobular and subsegmental areas 


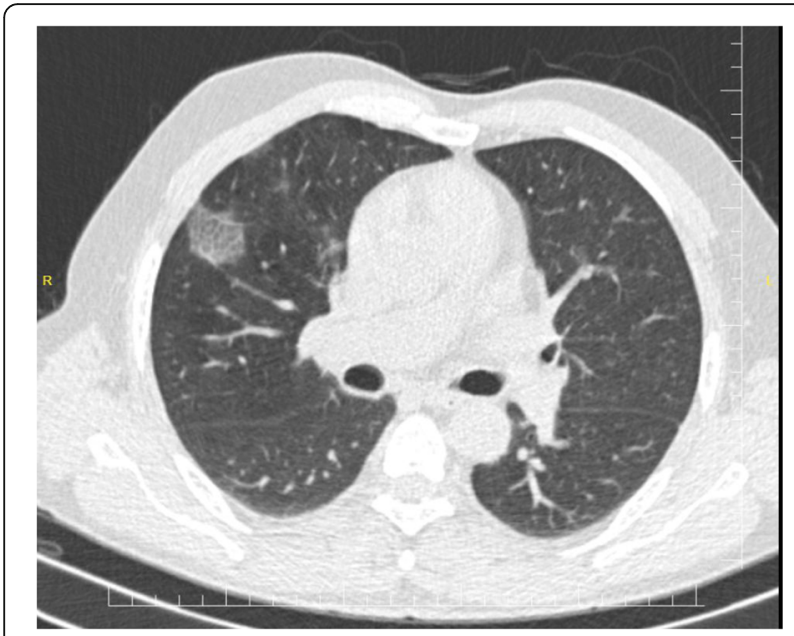

Fig. 2 An axial chest CT from a 50-year-old man with COViD-19 pneumonia. Non-contrast-enhanced chest CT image showed focal ground-glass opacity associated with smooth interlobular and intralobular septal thickening in the right upper lobe. The left lung was normal

Also, air bronchogram (Fig. 5) and lymphadenopathy were also noted (Table 2). Particularly, lung cavitation, discrete pulmonary nodules, pleural effusions, and underlying pulmonary fibrosis or emphysema were not observed.

\section{Discussion}

In this study, we investigated the clinical characteristics and radiographic features of COVID-19 pneumonia in adults, besides those from pregnant women. Our study found that COVID-19 patients had a variety of clinical and radiological manifestations. Cough, fever, myalgia, and sore throat were the most common clinical manifestations in our study similar to previous studies $[4,5]$. Other non-specific symptoms included SOB, diarrhea,

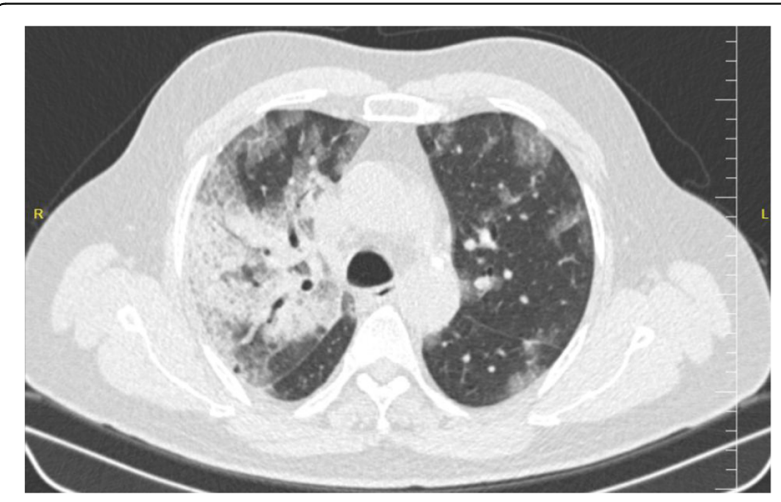

Fig. 3 An axial chest CT from a 60-year-old man with COVID-19 pneumonia. Non-contrast-enhanced chest CT image showed multiple peripheral ground-glass opacities distributed in the bilateral lung fields, combined with consolidation

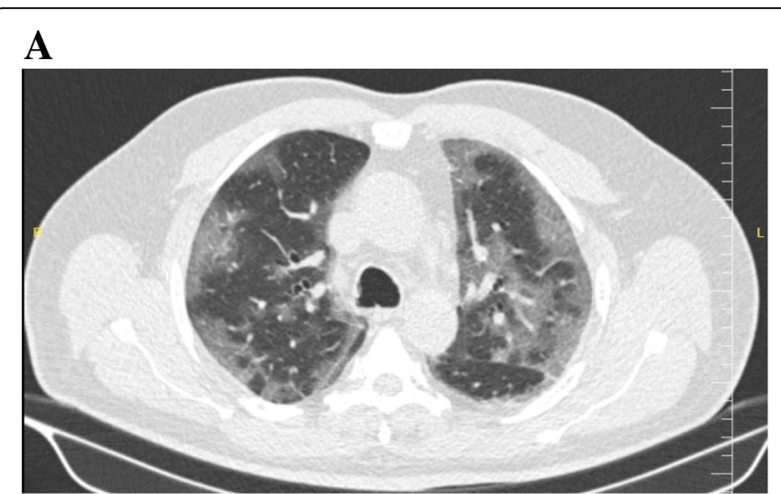

B

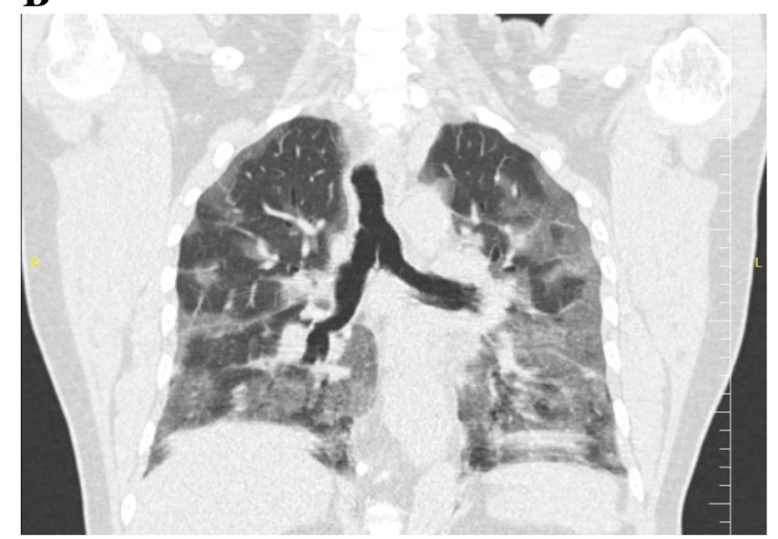

Fig. 4 Axial unenhanced chest CT image (a) and coronal reconstructed unenhanced chest $C T$ image (b) from a 57-year-old man with COVID-19 pneumonia noted widespread ground-glass and consolidative opacities in both lungs with a bilateral, peripheral, and basal predominant distribution

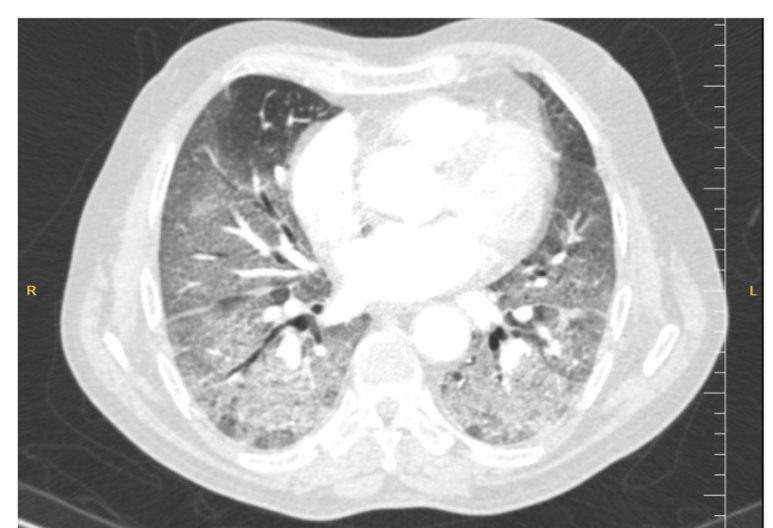

Fig. 5 An axial chest CT from a 60-year-old man with COViD-19 pneumonia. Non-contrast-enhanced chest CT image demonstrated extensive ground-glass opacities seen in both lungs, involving almost all lower lobes, giving a white lung appearance, with air bronchograms 
vomiting, nausea, and headache which occurred in around $7-18 \%$ of patients.

Chest CT is an essential part of the diagnostic investigation for patients with suspected COVID-19 infection, although very few cases have normal chest CT findings at the early stage [9]. However, our study has shown variants of chest CT findings in affected patients. Twenty-three of 27 (85.1\%) symptomatic patients had abnormal chest CT, while $2(7.4 \%)$ of $4(14.8 \%)$ asymptomatic patients had normal chest $\mathrm{CT}$ and none of them had any comorbid disease. Based on recently published data, most of the patients with COVID-19 had characteristics of chest CT features in the disease process such as ground-glass opacities (GGOs), mixed GGC, crazy paving pattern, consolidation, air bronchogram, bronchial dilatation, reticular pattern, and subpleural linear opacity [10-12].

In the present study, the most commonly observed opacification in patients with COVID-19 was GGO in 20 (74.1\%), which appeared predominantly in the peripheral zones and most often involved lower lung lobes and segments which are consistent with the results of previous studies of COVID19 and other viruses including SARS and MERS [13-15]. Furthermore, the most common characteristics of chest CT features associated with COVID-19 pneumonia in the elder group (> 60 years) included GGO with consolidation or reticular pattern, and consolidation with predominantly peripheral distribution and bilateral lung involvement, which was similar to the previous studies $[16,17]$.

In our study, we had several limitations; first, it was a retrospective study, and we had a comparatively small number of 27 patients. On the one hand, we only analyzed the clinical and chest CT manifestations at the initial presentation. Further studies are needed including clinical and radiological follow-ups.

Second, not all laboratory tests were done in all patients, including procalcitonin, AST, ALT, creatinine, urea, albumin, procalcitonin, D-dimer, lactate dehydrogenase, and serum ferritin.

Finally, the article only included non-pregnant adults. The clinical characteristics and radiological findings of pregnant women and children infected with COVID-19 are not clear.

\section{Conclusion}

This study represents an early investigation of clinical characteristics and chest CT findings in patients with 2019 novel coronavirus (2019-nCoV). Dry cough, fever, myalgia, and sore throat were the most clinical presentations.

GGO, crazy paving pattern, patchy consolidation, and mixed GCO were typical chest CT manifestations. The most common predominant lesion distributions were bilateral, peripheral and lower lung zone predominance. A small number of patients with COVID-19 pneumonia had had no obvious symptoms, and there chest CT scans were normal.

\section{Acknowledgements}

To a specialist at the radiology department who helped in reviewing the patient's CT scan findings.

\section{Authors' contributions}

Y.G.M. and M.F.Y.M.: writing of the manuscript; final revision of the data, statistical tables, and radiological images; and finalization of the research manuscript. M.S.M.: idea of the research, supervision, and revision of the data. I.Y.A.: helped in the radiological examination of patients and revision of the data. I.H.A.: collected the data and helped in the writing of the manuscript. All authors read and approved the final manuscript.

\section{Funding}

We declare that we have no funding source.

\section{Availability of data and materials}

The data that support the findings of this study are available from Mogadishu Somali Turkish Training and Research Hospital. Data are however available from the authors upon reasonable request and with permission from Mogadishu Somali Turkish Training and Research Hospital.

\section{Ethics approval and consent to participate}

We obtained an approval letter from the review board of Mogadishu Somali Turkish Training and Research Hospital, and written informed consent was waived (MSTH/3712) because the study was retrospective and collected from medical records. We declare that we have followed the protocols of our work center. Patient data confidentiality was respected.

Consent for publication

Not applicable.

\section{Competing interests}

We declare that we have no competing interests and funding source.

\section{Author details}

${ }^{1}$ Mogadishu Somali Turkish Training and Research Hospital, Mogadishu, Somalia. ${ }^{2}$ Mogadishu Somali Turkish Training and Research Hospital, 30 Street, Alikamin, Wartanabada District, Mogadishu, Somalia.

Received: 12 May 2020 Accepted: 24 August 2020

Published online: 11 September 2020

\section{References}

1. Huang C, Wang Y, Li X, Ren L, Zhao J, Hu Y, Zhang L, Fan G, Xu J, Gu X, Cheng Z (2020) Clinical features of patients infected with 2019 novel coronavirus in Wuhan, China. Lancet. 395(10223):497-506

2. Zhu N, Zhang D, Wang W, Li X, Yang B, Song J, Zhao X, Huang B, Shi W, Lu R, Niu P A novel coronavirus from patients with pneumonia in China, 2019, New England Journal of Medicine. 2020

3. WHO Director-General's opening remarks at the media briefing on COVID 19 https://www.who.int/dg/speeches/detail/who-director-general-sopening-remarks-at-the-media-briefingon-covid-1 9\%2D\%2D-11-march-2020.

4. Chen N, Zhou M, Dong X, Qu J, Gong F, Han Y, Qiu Y, Wang J, Liu Y, Wei Y, Yu T (2020) Epidemiological and clinical characteristics of 99 cases of 2019 novel coronavirus pneumonia in Wuhan, China: a descriptive study. Lancet 395(10223):507-513

5. Huang C et al (2020) Clinical features of patients infected with 2019 novel coronavirus in Wuhan, China. Lancet 395(10223):497-506

6. Chung M, Bernheim A, Mei X, Zhang N, Huang M, Zeng X, Cui J, Xu W, Yang Y, Fayad ZA, Jacobi A (2020) CT imaging features of the 2019 novel coronavirus (2019-nCoV). Radiology. 295(1):202-207

7. Chavez S, Long B, Koyfman A, Liang SY (2020) Coronavirus disease (COVID19): a primer for emergency physicians. Am J Emerg Med

8. Hansell DM, Bankier AA, MacMahon H, McLoud TC, Muller NL, Remy J (2008) Fleischner Society: glossary of terms for thoracic imaging. Radiology. 246(3): 697-722

9. Kanne JP, Little BP, Chung JH, Elicker BM, Ketai LH (2020) Essentials for radiologists on COVID-19: an update-radiology scientific expert panel [published online ahead of print, 2020 Feb 27]. Radiology:200527

10. Lei J, Li J, Li X et al (2020) CT imaging of the 2019 novel coronavirus (2019nCoV) pneumonia. Radiology. https://doi.org/10.1148/radiol.2020200236 
11. Huang P, Liu T, Huang $L$ et al (2020) Use of chest $C T$ in combination with negative RT-PCR assay for the 2019 novel coronavirus but high clinical suspicion. Radiology. https://doi.org/10.1148/radiol.2020200330

12. Cheng $Z$ et al (2020) Clinical features and chest $C T$ manifestations of coronavirus disease 2019 (COVID-19) in a single-center study in Shanghai, China. Am J Roentgenol:1-6

13. Zhao W, Zhong Z, Xie X, Yu Q, Liu J (2020) Relation between chest CT findings and clinical conditions of coronavirus disease (COVID-19) pneumonia: a multicenter study. Am J Roentgenol 19:1-6

14. Wong KT, Antonio GE, Hui DS, Lee N, Yuen EH, Wu A, Leung CB, Rainer TH, Cameron P, Chung SS, Sung JJ (2003) Thin-section CT of severe acute respiratory syndrome: evaluation of 73 patients exposed to or with the disease. Radiology. 228(2):395-400

15. Gao F, Li M, Ge X, Zheng X, Ren Q, Chen Y, Lv F, Hua Y (2013) Multidetector spiral CT study of the relationships between pulmonary ground-glass nodules and blood vessels. Eur Radiol 23(12):3271-3277

16. Chung M, Bernheim A, Mei X, Zhang N, Huang M, Zeng X, Cui J, Xu W, Yang Y, Fayad ZA, Jacobi A (2020) CT imaging features of 2019 novel coronavirus (2019-nCoV). Radiology. 295(1):202-207

17. Song F, Shi N, Shan F, Zhang Z, Shen J, Lu H, Ling Y, Jiang Y, Shi Y (2020) Emerging 2019 novel coronavirus (2019-nCoV) pneumonia. Radiology. 295(1):210-217

\section{Publisher's Note}

Springer Nature remains neutral with regard to jurisdictional claims in published maps and institutional affiliations.

\section{Submit your manuscript to a SpringerOpen ${ }^{\circ}$ journal and benefit from:}

- Convenient online submission

- Rigorous peer review

- Open access: articles freely available online

High visibility within the field

- Retaining the copyright to your article

Submit your next manuscript at $\boldsymbol{\nabla}$ springeropen.com 